\title{
Heat conduction from the exceedingly hot fiber tip contributes to the endovenous laser ablation of varicose veins
}

Renate R. van den Bos • Michael A. Kockaert •

H. A. Martino Neumann • Rolf H. Bremmer •

Tamar Nijsten • Martin J. C. van Gemert

Published online: 4 April 2009

(C) Springer-Verlag London Limited 2009

\section{Erratum to: Lasers Med Sci}

\section{DOI 10.1007/s10103-008-0639-y}

Unfortunately Fig. 3 was omitted and Fig. 2 was repeated in its place.

The correct Fig. 3 is reproduced here.

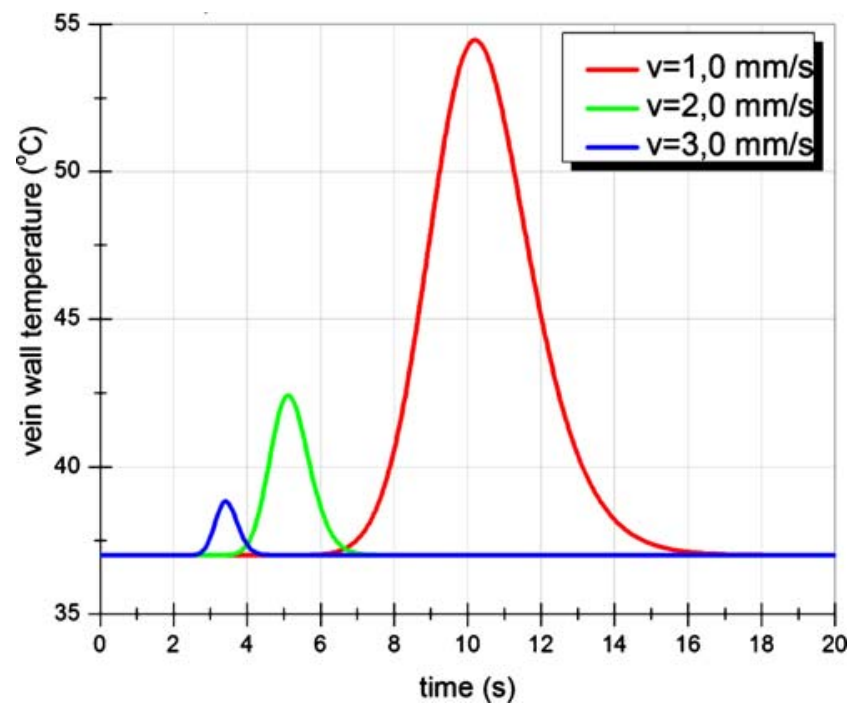

Fig. 3 As Fig. 2, now for a vein radius of $\mathrm{r}=2.5 \mathrm{~mm}$ and $\mathrm{T}_{\text {tip }}=1,000^{\circ} \mathrm{C}$

The online version of the original article can be found at http://dx.doi. org/10.1007/s10103-008-0639-y.

R. R. van den Bos • M. A. Kockaert · H. A. Martino Neumann •

T. Nijsten $(\bowtie)$

Department of Dermatology, Erasmus Medical Centre,

P.O. BOX 2040, 3000 CA Rotterdam, The Netherlands

e-mail: t.nijsten@erasmusmc.nl

R. H. Bremmer • M. J. C. van Gemert

Department of Biomedical Engineering and Physics,

Academic Medical Centre,

Amsterdam, The Netherlands 